\title{
Specific Light-Emitting Diodes Can Suppress Sporulation of Podosphaera pannosa on Greenhouse Roses
}

\author{
A. Suthaparan and S. Torre, Department of Plant and Environmental Sciences, Norwegian University of Life Sci- \\ ences, 1432 Ås, Norway; A. Stensvand, Department of Plant and Environmental Sciences, Norwegian University of \\ Life Sciences, and Norwegian Institute for Agricultural and Environmental Research, Høgskoleveien 7, 1432 Ås, \\ Norway; M. L. Herrero, Norwegian Institute for Agricultural and Environmental Research; R. I. Pettersen, De- \\ partment of Plant and Environmental Sciences, Norwegian University of Life Sciences; D. M. Gadoury, Department \\ of Plant Pathology and Plant-Microbe Biology, Cornell University, New York State Agricultural Experiment Station, \\ Geneva, NY 14456; and H. R. Gislerød, Department of Plant and Environmental Sciences, Norwegian University of \\ Life Sciences
}

\begin{abstract}
Suthaparan, A., Torre, S., Stensvand, A., Herrero, M. L., Pettersen, R. I., Gadoury, D. M., and Gislerød, H. R. 2010. Specific light-emitting diodes can suppress sporulation of Podosphaera pannosa on greenhouse roses. Plant Dis. 94:1105-1110.

When rose plants bearing colonies of Podosphaera pannosa were placed in a wind tunnel, the number of conidia trapped was directly proportional to intensity of daylight-balanced (white) light from 5 to $150 \mu \mathrm{mol} \mathrm{m} \mathrm{m}^{-2} \mathrm{~s}^{-1}$. Illumination of samples using blue (420 to $520 \mathrm{~nm}$ ) lightemitting diodes (LEDs) increased the number of conidia trapped by a factor of approximately 2.7 over white light but germination of conidia under blue light was reduced by approximately $16.5 \%$ compared with conidia germination under white light. The number of conidia trapped under far-red ( $>685 \mathrm{~nm}$ ) LEDs was approximately 4.7 times higher than in white light, and 13.3 times higher than under red (575 to $675 \mathrm{~nm}$ ) LEDs, and germination was not induced compared with white light. When mildewed plants were exposed to cycles of $18 \mathrm{~h}$ of white light followed by $6 \mathrm{~h}$ of blue, red, far-red light, or darkness, light from the red LEDs reduced the number of conidia trapped by approximately $88 \%$ compared with darkness or far-red light. Interrupting the above dark period with $1 \mathrm{~h}$ of light from red LEDs also reduced the number of conidia trapped, while a 1-h period of light from far-red following the $1 \mathrm{~h}$ of light from red LEDs nullified the suppressive effect of red light. Our results indicate that brief exposure to red light during the dark interval may be as effective as continuous illumination in suppressing powdery mildew in greenhouse rose plant $($ Rosa $\times$ hybrida $)$.
\end{abstract}

In Northern Europe, greenhouse rose $($ Rosa $\times$ hybrida) production requires supplemental lighting during winter months due to short day length and relatively low natural light intensity (9). Powdery mildew caused by Podosphaera pannosa (Wallr.:Fr.) de Bary is one of the most serious diseases of greenhouse-grown rose plants, reducing both plant vigor and esthetic value. Rose growers in Northern Europe generally rely upon evaporated sulfur or direct applications of synthetic fungicides to control powdery mildew. Although usually effective, use of either tactic can be problematic. Many fungicides, and particularly sulfur, may interfere with natural predators deployed to control insect and mite pests (1). Furthermore, resistance to both demethylation inhibitors

Corresponding author: D. M. Gadoury

E-mail: dmg4@cornell.edu

Accepted for publication 16 May 2010.

doi:10.1094/PDIS-94-9-1105

(C) 2010 The American Phytopathological Society and strobilurins; two of the most widely used groups of synthetic fungicides used for management of rose powdery mildew, has recently been reported for $P$. pannosa (5).

We recently demonstrated that increasing the length of the daylight period to 20 to 24 $\mathrm{h}$ using supplemental lighting significantly reduced both sporulation of $P$. pannosa and rose plants $(17,18)$. However, cost of energy required to provide such supplemental lighting through the fixtures customarily used for plant growth could make the application of this strategy prohibitively expensive. Therefore, we sought to maximize the efficiency of this approach to disease management by quantifying the effects of light intensity and quality during supplemental lighting upon $P$. pannosa, upon suppression of disease, and by providing specifically suppressive wavelengths of light using lowenergy light-emitting diodes (LEDs). Preliminary accounts of this work have been published (19).

\section{MATERIALS AND METHODS}

Production of host plant material. Mildew-free potted miniature rose plants severity of powdery mildew in greenhouse
(Rosa $\times$ hybrida $\mathrm{cv}$. Mistral) were grown in limed and fertilized peat (Floralux, Nittedal torv industri A/S, Norway) and Perlite $(25 \%$ by volume) in a greenhouse compartment to produce plant material for the experiments. Mercury lamps (Powerstar HQI-BT 400W/D day light; OSRAM $\mathrm{GmbH}$, Augsburg, Germany) at photon flux densities (PFDs) (400 to $700 \mathrm{~nm}$ ) of $200 \mu \mathrm{mol} \mathrm{m} \mathrm{m}^{-2} \mathrm{~s}^{-1}$ recorded at top of the plants were used as a supplementary light source (18 h per day). The lights were automatically turned off when natural light exceeded $200 \mu \mathrm{mol} \mathrm{m} \mathrm{m}^{-2} \mathrm{~s}^{-1}$. Temperature was set at $20^{\circ} \mathrm{C}$ and relative humidity ( $\left.\mathrm{RH}\right)$ at $80 \%$. Plants were exposed to evaporated sulfur for $4 \mathrm{~h}$ per day during the night and watered with complete nutrient solution when needed. The plants were pruned to induce young active shoot growth to ensure sufficient supply of uniformly aged mildew-free leaflets.

Production of inoculum. Mildewed rose leaves were obtained from a commercial greenhouse located in southeastern Norway, and the pathogen was transferred to newly unfolded detached rose leaflets as follows. Leaflets were surface sterilized as previously described (18) and were placed in petri dishes containing water agar. The leaflets were then inoculated by touching them gently with mildewed leaves obtained from a commercial greenhouse Detached leaflets were subsequently incubated for 7 days as described (18). Isolates were subsequently subcultured and transferred twice more to reduce the presence of contaminating fungi (18), and were maintained by periodic transfer to diseasefree plants in an isolated growth chamber. Environmental conditions in the growth chamber were as described above for production of host plant material. Inoculum for all experiments consisted of conidia from 7-day-old cultures of powdery mildew grown on detached leaves prepared as described previously (18).

Influence of light quality on germination and formation of conidia on detached leaflets. Studies of the effect of light quality on conidial germination and sporulation in vitro took place in four 
growth chambers with an 18-h day length. Chambers were equipped with LEDs of either blue (Model QB-2001-A), red (Model QB-2200-A), far-red (Model QBveld, WI), or white (full-spectrum) mercury lamps (Powerstar HQI-BT 400W/D day light; OSRAM $\mathrm{GmbH}$ ) with light spectrums of blue (420 to $520 \mathrm{~nm}$, peak $465 \mathrm{~nm}$ ), red (620 to $720 \mathrm{~nm}$, peak 675 $\mathrm{nm}$ ), far-red (685 to $780 \mathrm{~nm}$, peak 755 $\mathrm{nm}$ ), and full-spectrum white light. The PFDs were $3.6 \mu \mathrm{mol} \mathrm{m} \mathrm{m}^{-2} \mathrm{~s}^{-1}$ for the LED lamps and $5 \mu \mathrm{mol} \mathrm{m}{ }^{-2} \mathrm{~s}^{-1}$ for the mercury lamps. Wire mesh was used to reduce the white-light level from 50 to $5 \mu \mathrm{mol} \mathrm{m}{ }^{-2} \mathrm{~s}^{-1}$. Temperature was kept at $20 \pm 2^{\circ} \mathrm{C}$. Detached leaflets (abaxial surface uppermost) on water agar were kept in the upper part of the dual-chamber boxes with a lid. Saturated $\mathrm{KCl}$ salt solution in the lower part of the dual-chamber boxes provided a constant humidity in the upper chamber containing the leaflets $(96 \pm 2 \% \mathrm{RH})(18)$.

For germination tests, three of the above dual-chamber boxes, each containing six 2200-A) (Quantum Devices, Inc., Barne-

healthy leaflets, were placed in each of four growth chambers. Each chamber provided a different light quality. Immediately before they were illuminated, the leaflets were inoculated by touching them gently with source inoculum leaflets, with a separate sporulating leaflet used to apply conidia to each healthy leaflet. Four leaflets from each treatment were removed $24 \mathrm{~h}$ after inoculation and frozen at $-2{ }^{\circ} \mathrm{C}$ until further examination. The leaflets were then prepared for microscopic observation, and germination was assessed (18). Germination was assessed for 50 conidia from each leaflet. Conidia were counted as germinated if the length of the germ tube was greater than or equal to one-half the length of the conidium.

For conidial production tests, leaflets in the above-described boxes were inoculated by placing one drop $(15 \mu \mathrm{l})$ of a spore suspension (approximately $4.5 \times 10^{4}$ spores $/ \mathrm{ml}$ ) on each leaflet. Immediately after inoculation, the humidity boxes were first kept for 4 days at 18-h day length provided by mercury lamps (same type as de-

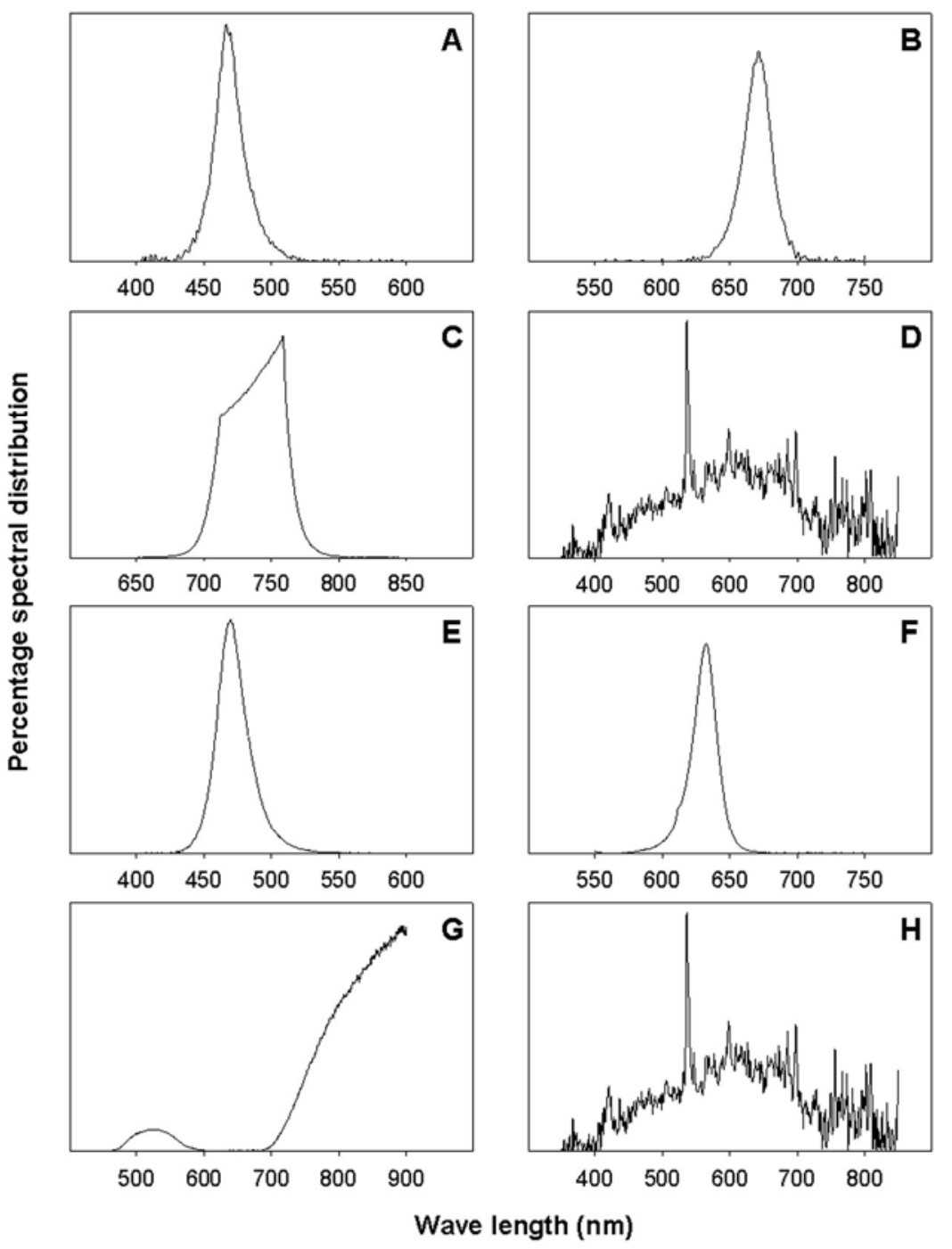

Fig. 1. Spectral distribution of A, blue; $\mathbf{B}$, red; $\mathbf{C}$, far-red; and $\mathbf{D}$, white light sources used in conidia germination and formation experiments in conjunction with dual-chamber humidity boxes and spectral distribution of $\mathbf{E}$, blue; $\mathbf{F}$, red; $\mathbf{G}$, far-red; and $\mathbf{H}$, white light sources used in wind tunnel experiments. scribed above) with PFD of $50 \mu \mathrm{mol} \mathrm{m} \mathrm{m}^{-2} \mathrm{~s}^{-1}$. Temperature was kept at $20 \pm 2{ }^{\circ} \mathrm{C}$. Then, three boxes were transferred to each of the four growth chambers where they were exposed to either blue, red, far-red, or white light. Six leaflets with sporulating powdery mildew colonies from each treatment were randomly removed 9 days after inoculation, placed in 50-ml centrifuge tubes containing $5 \mathrm{ml}$ of distilled water, and shaken by hand for $2 \mathrm{~min}$. The leaflets were removed from the centrifuge tube and conidia in the resultant suspensions were enumerated by examining three subsamples of spore suspension per tube using a hemacytometer at $\times 200$. The experiment was conducted two times, and the factors of lighting treatment, experimental repeat, and replicates were included in the data analysis.

Influence of light quality on formation and release of conidia on whole plants. Studies of the effects of light quality and light intensity on conidial productivity (combined effect of conidia formation and release, recorded as number of conidia trapped) took place in small wind tunnels (18) placed within four growth chambers with RH $80 \pm 5 \%$ and temperature $20 \pm 2^{\circ} \mathrm{C}$. Mercury lamps (as described above) were used as the white-light source. LED lamps (Affinium string kit IP 66, Philips, The Netherlands) were used as blue and red light sources. Two incandescent 60-W lamps (OSRAM, GmbH) with dark-green filters (no. 124; Lee Filters, Burbank, CA) were used as the far-red light source. These light sources provided the spectrum of blue ( 420 to $520 \mathrm{~nm}$, peak $465 \mathrm{~nm}$ ), red (575 to $675 \mathrm{~nm}$, peak 630 $\mathrm{nm})$, far-red $(>685 \mathrm{~nm})$, and full-spectrum for white light (Fig. 1). The PFD light levels of all lamps were $5 \mu \mathrm{mol} \mathrm{m} \mathrm{m}^{-2} \mathrm{~s}^{-1}$. Wire mesh was used to reduce the whitelight level from 50 to $5 \mu \mathrm{mol} \mathrm{m} \mathrm{m}^{-2} \mathrm{~s}^{-1}$.

Plants of uniform size were inoculated with 1-week-old powdery mildew inoculum in a conidial suspension as previously described (18) at the rate of $2.5 \mathrm{ml}$ for each plant. These inoculated plants were kept at $18 \mathrm{~h}$ of day length provided by mercury lamps at $200 \mu \mathrm{mol} \mathrm{m}^{-2} \mathrm{~s}^{-1}, 20^{\circ} \mathrm{C}$ and $80 \%$ RH for 12 days. For each run of an experiment, two plants were placed in each of the wind tunnels. Conidia released from the plants in the wind tunnel were trapped on a plastic tape attached to a 24-h rotating clock cylinder with a circumference of 288 $\mathrm{mm}$ (rotating four times $=4$ days), providing continuous readings of conidial formation and release (18). Lacto fuchsin was used to stain the conidia trapped on the plastic tape. The tape was scanned perpendicular to the direction of rotation at 2-mm (10-min) intervals at $\times 200$ magnification under a compound light microscope (total of 144 transects per day). The counts from these transects were further pooled within eight 3 -h periods (i.e., 0 to $0300 \mathrm{~h}, 0300$ to $0600 \mathrm{~h}, 0600$ to $0900 \mathrm{~h}$, and so on) and the 
factors of lighting treatment, experimental repeat, and time period were included in the data analysis.

Plants in wind tunnels were exposed to the following lighting treatments: (i) all plants were provided $18 \mathrm{~h}$ of either blue, red, far-red, or white light with PFD of 5 $\mu \mathrm{mol} \mathrm{m} \mathrm{m}^{-2} \mathrm{~s}^{-1}$; (ii) all plants were provided $18 \mathrm{~h}$ of white light by mercury lamps (PFD of $50 \mu \mathrm{mol} \mathrm{m} \mathrm{m}^{-2} \mathrm{~s}^{-1}$ ) followed by $6 \mathrm{~h}$ of either blue, red, or far-red light at PFD of 5 $\mu \mathrm{mol} \mathrm{m} \mathrm{m}^{-2} \mathrm{~s}^{-1}$, or darkness; (iii) all plants were exposed to $18 \mathrm{~h}$ of white light (50 $\mu \mathrm{mol} \mathrm{m} \mathrm{m}^{-2} \mathrm{~s}^{-1}$ ) followed by $6 \mathrm{~h}$ of darkness or with 1-h night breaks with either red, far-red, or red + far-red light at PFD of 5 $\mu \mathrm{mol} \mathrm{m} \mathrm{m}^{-2} \mathrm{~s}^{-1}$ (Fig. 2); (iv) all plants were given $18 \mathrm{~h}$ of white light with mercury lamps but PFDs for the different treatments were set to either $5,50,100$, or 150 $\mu \mathrm{mol} \mathrm{m} \mathrm{m}^{-2} \mathrm{~s}^{-1}$.

Recording of environmental parameters. Light intensity was recorded under the top (facing the light source) of the petri dishes or dual-chamber humidity boxes in the detached leaf experiments and on top of the plants in the whole-plant experiments, and temperature and RH were recorded in the same compartments, all with instrumentation as described previously (18). Light quality was recorded inside (at the same height as for light intensity) and outside (on the top, facing the light source) the petri dish, dual-chamber humidity boxes, and wind tunnels with a Spectra Wiz spectrometer Model EPP 2000 Fiberoptic (Stellarnet Inc., Tampa, FL).

Statistical analysis. Minitab (version 14) was used to conduct the analysis of variance (GLM procedure) and comparisons of means (Bonferroni test at $P=$ $0.05)$.

\section{RESULTS}

Influence of light quality on germination and formation of conidia on detached leaflets. The mean percentage of conidia that germinated was significantly reduced $(P=0.001)$ in blue light $(51.75 \%)$ relative to the white-light control $(62 \%)$ (Fig. 3). Germination of conidia was not reduced by red or far-red light relative to the white-light control (Fig. 3).

The mean number of conidia enumerated in suspension was approximately 1.3 $\times 10^{4}$ conidia/ml under white light. Far-red light strongly stimulated production of conidia. The number of conidia formed on detached leaflets was $3 \times 10^{4}$ conidia $/ \mathrm{ml}$ when exposed to $18 \mathrm{~h}$ of far-red light, and it was approximately 2.3 times higher (significant at $P<0.0001$ ) compared with $18 \mathrm{~h}$ of white, red, or blue light (Fig. 4). No significant differences in the production of conidia were found among leaflets exposed to $18 \mathrm{~h}$ of blue $\left(1.1 \times 10^{4}\right)$, red $\left(1.3 \times 10^{4}\right)$, and white light (Fig. 4).

Influence of light quality on formation and release of conidia on whole plants. When whole plants were exposed

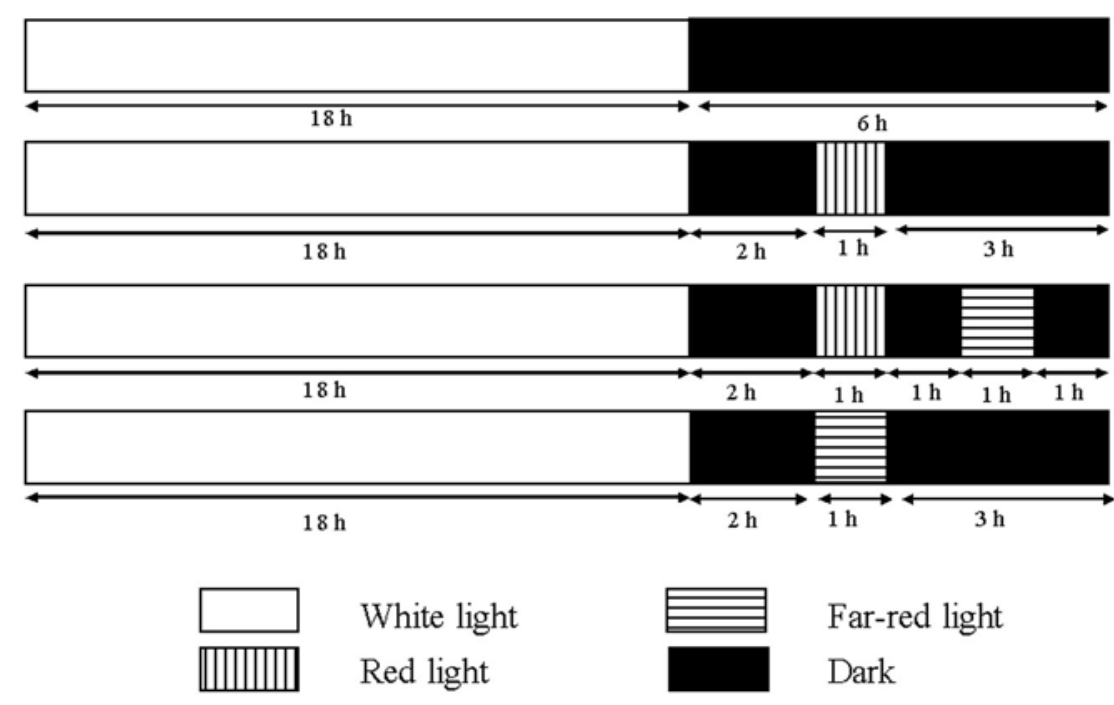

Fig. 2. Schematic illustration of short night-break treatments imposed in wind tunnel studies. Plants were exposed to white light for $18 \mathrm{~h}$ followed by a 6-h period in which the plants were in darkness for the entire $6 \mathrm{~h}$, or the dark period was interrupted by red light, red light followed by far-red light, or farred light.

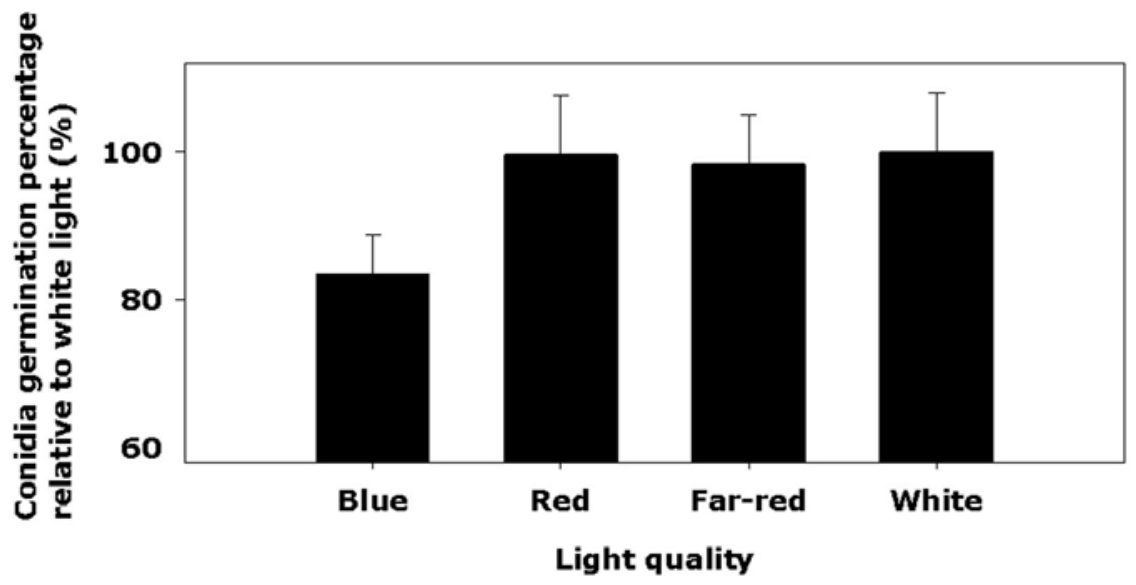

Fig. 3. Effect of light quality on germination of conidia of Podosphaera pannosa on detached leaflets of Rosa $\times$ hybrida cv. Mistral. Leaflets were exposed to $18 \mathrm{~h}$ of blue, red, far-red, or white light followed by $6 \mathrm{~h}$ of darkness (mean of two repeated experiments with four leaflets in each). Treatment means are reported as percentage of germination relative to the white-light control. Bars indicate one standard error of the mean.

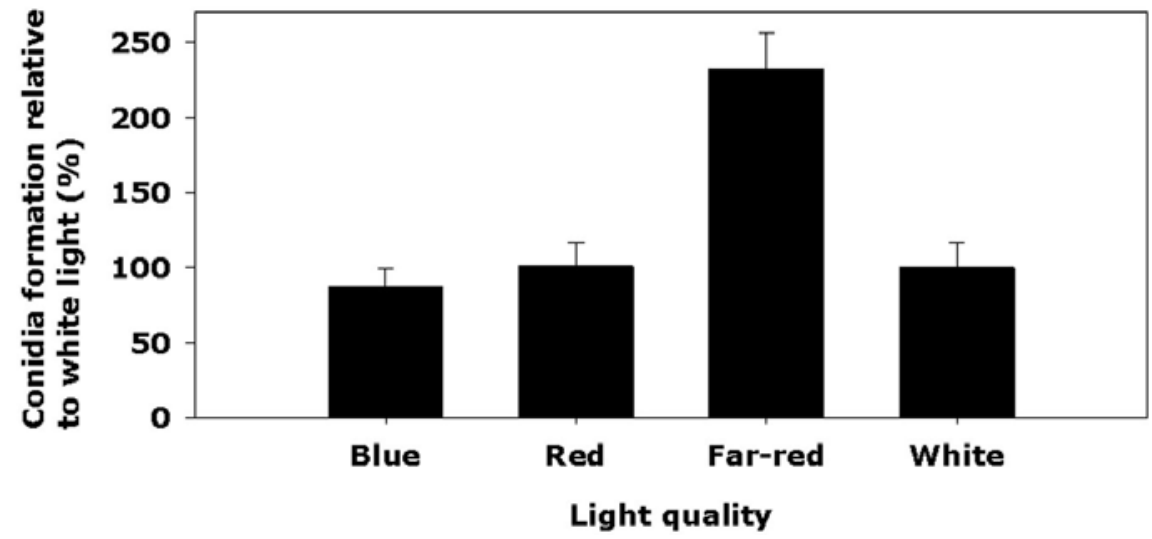

Fig. 4. Effect of light quality on formation of conidia by Podosphaera pannosa on detached leaflets of Rosa $\times$ hybrida cv. Mistral. Leaflets were inoculated and then exposed to $18 \mathrm{~h}$ of white light per $24 \mathrm{~h}$ for 4 days, then transferred to cycles of $18 \mathrm{~h}$ with either blue, red, far-red, or white light followed by 6 $\mathrm{h}$ of darkness. Conidia were enumerated 9 days after inoculation (mean of repeated experiments). Treatment means are reported as percentages relative to white-light control. Bars indicate one standard error of the mean. 
in wind tunnels to diurnal cycles incorporating $18 \mathrm{~h}$ of low-intensity (PFD $5 \mu \mathrm{mol}$ $\mathrm{m}^{-2} \mathrm{~s}^{-1}$ ) blue, red, far-red, or white light followed by $6 \mathrm{~h}$ of darkness, blue, and farred light significantly $(P=0.029)$ stimulated productivity (formation and release) of conidia compared with the white-light control. There was no significant difference between red and white light (Fig. 5).

When whole plants were exposed in wind tunnels to diurnal cycles of $18 \mathrm{~h}$ of high-intensity (PFD $50 \mu \mathrm{mol} \quad \mathrm{m}^{-2} \mathrm{~s}^{-1}$ ) white light followed by $6 \mathrm{~h}$ of lowintensity (PFD $5 \mu \mathrm{mol} \mathrm{m} \mathrm{m}^{-2} \mathrm{~s}^{-1}$ ) light of either blue, red, far-red, or darkness; the number of conidia trapped was significantly $(P<0.0001)$ reduced only by red light (Fig. 6). The total number of conidia trapped under $18 \mathrm{~h}$ of high-intensity white light followed by $6 \mathrm{~h}$ of low-intensity red light treatment were 306 (mean of three experiments). There was no significant suppression of conidial productivity by darkness, far-red, or blue light, where a mean of 2,429, 2,518, and 1,915 conidia were enumerated, respectively. A 1-h exposure to red light during the dark period was as effective as continuous light (18) in suppressing productivity of conidia (Fig. 7; $P<0.0001)$. When plants were exposed to $18 \mathrm{~h}$ of white light followed by $6 \mathrm{~h}$ of darkness, the total number of conidia trapped during the 4 days was 6,253 (mean of three experiments) compared with a mean of 2,042 conidia trapped when the night period was interrupted with $1 \mathrm{~h}$ of low-intensity red light. Furthermore, the suppressive effect of red light was reversed by $1 \mathrm{~h}$ of far-red light (Fig. 7), after which a mean of 5,403 conidia were trapped.

When plants were supplied with $18 \mathrm{~h}$ of white light followed by a 6-h dark period, the number of conidia trapped in the wind tunnels was directly proportional to light intensity of 5 to $150 \mu \mathrm{mol} \mathrm{m} \mathrm{m}^{-2} \mathrm{~s}^{-1}$ (Fig. 8). The total number of conidia trapped under

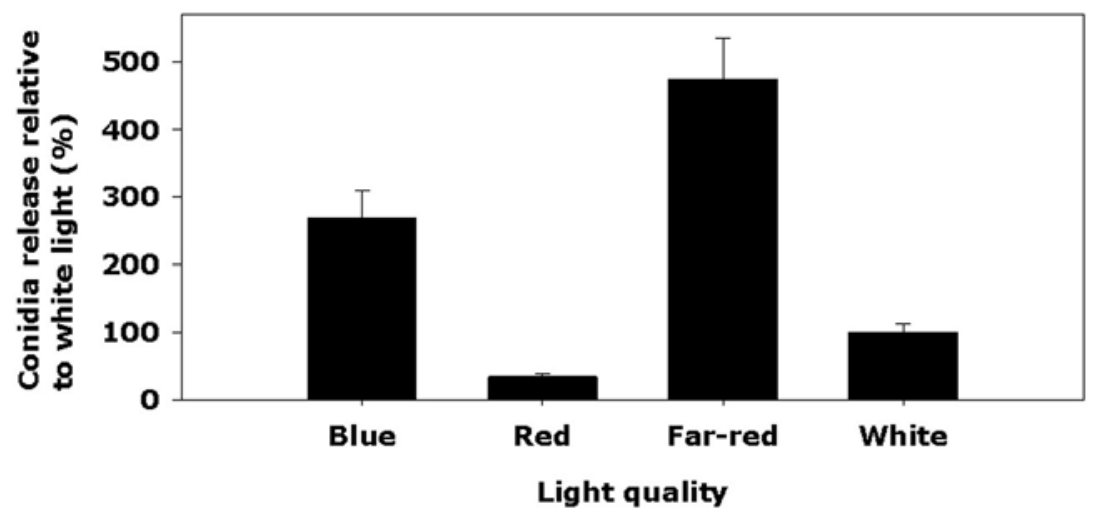

Fig. 5. Effect of light quality on conidia productivity (formation and release) of Podosphaera pannosa on whole plants of Rosa $\times$ hybrida cv. Mistral in wind tunnels. Inoculated plants (kept at $18 \mathrm{~h}$ of day length) bearing 12-day-old colonies were exposed to $18 \mathrm{~h}$ of blue, red, far-red, or white light followed by $6 \mathrm{~h}$ of darkness for 4 days (experiment was repeated three times). Treatment means are reported as percentages relative to the white-light control. Bars indicate one standard error of the mean.

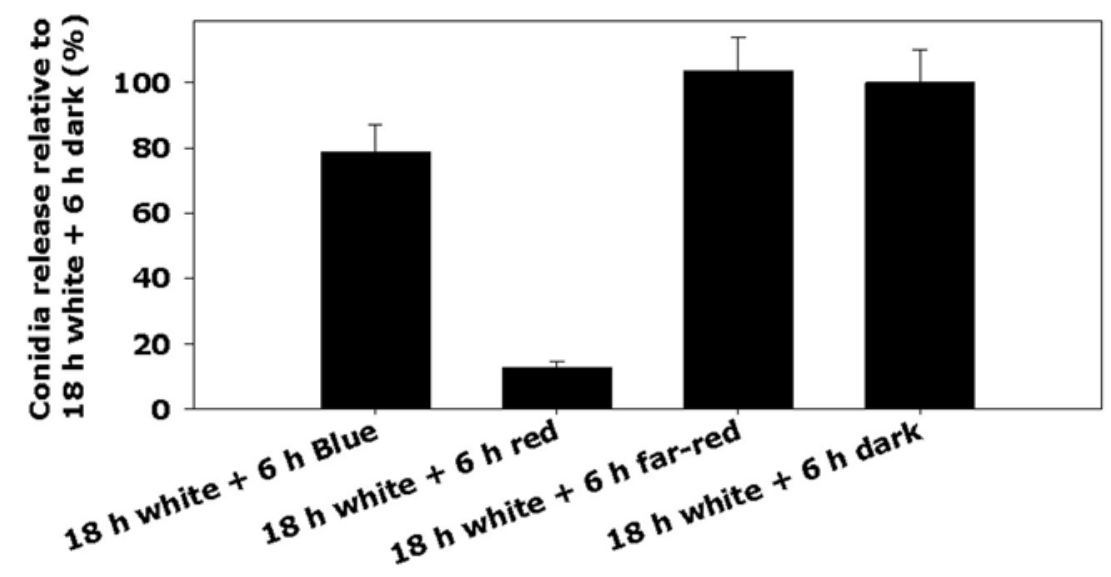

\section{Light quality}

Fig. 6. Effect of extension of day length using different light qualities on productivity (formation and release) of conidia by Podosphaera pannosa on whole plants of Rosa $\times$ hybrida. Inoculated plants (kept at $18 \mathrm{~h}$ of day length) bearing 12-day-old colonies were exposed to 4 cycles (days) of $18 \mathrm{~h}$ of white light followed by $6 \mathrm{~h}$ of either blue, red, or far-red light or darkness in wind tunnels (experiment was repeated three times). Treatment means are reported as percentages relative to $18 \mathrm{~h}$ of white light $+6 \mathrm{~h}$ of darkness (control). Bars indicate one standard error of the mean.

a light intensity of $5 \mu \mathrm{mol} \mathrm{m} \mathrm{m}^{-2} \mathrm{~s}^{-1}$ was 239 (mean of three experiments) compared with 1,486, 2,384, and 5,275 conidia trapped at light intensities of 50,100, and $150 \mu \mathrm{mol} \mathrm{m} \mathrm{m}^{-2} \mathrm{~s}^{-1}$, respectively. Linear regression of natural log-transformed numbers of conidia trapped during 4 days against light intensity (Fig. 8) yielded an $R^{2}$ of 0.71 with a slope coefficient that was significant at $P<0.0001$ (Fig. 8).

\section{DISCUSSION}

Rose powdery mildew is a polycyclic disease with the potential to spread rapidly, especially within greenhouse production systems. Spread of the disease depends on abundant and nearly continuous production of conidia. Our previous research showed that rose powdery mildew could be suppressed by management of lighting in greenhouse production; specifically, that sporulation of the pathogen was suppressed under continuous light (18). In the present study, we have further clarified the quantity and quality of light required for suppression of sporulation, and have also illustrated which components of the visible spectrum actually stimulate sporulation.

Low-energy LEDs may provide means of supplying mildew-suppressive lighting to rose plants without the potentially prohibitive cost of continuous lighting used in our earlier studies $(18,19)$. LED technology $(4,11)$ makes it possible to provide the specific spectrum of red light required to suppress sporulation, and to do so at an intensity far below the energy levels required for plant growth. Thus, apart from energy costs, day extension using lowenergy red LEDs may be more desirable for its lower potential to interfere with plant development. Although red light is important for the development of the photosynthetic apparatus, it can also induce thicker leaves and promote axillary bud growth $(10,15)$, and far-red light can result in thin leaf formation, elongation of internodes, and reduced axillary bud growth $(2,10)$. Reduced postharvest keeping quality in rose plants due to stomatal malfunction is also a potential side effect of continuous exposure to white light if relative humidity remains high during exposure (12). At low PFDs (e.g., below $15 \mu \mathrm{mol}$ $\mathrm{m}^{-2} \mathrm{~s}^{-1}$ ), red light has not affected stomatal opening or resulted in reduced stomatal conductance in previous studies $(7,21)$.

Reduced lesion growth and conidial formation in response to manipulation of light exposure have been reported for other powdery mildews. Reduced severity of cucumber powdery mildew caused by $P$. fusca (syn. Sphaerotheca fusca) was observed under polythene films that blocked far-red and UV light (6). Cucumber plants inoculated with $P$. xanthii (syn. S. fuliginea) and grown under light of different spectral composition developed the highest number of powdery mildew colonies per leaf under broad-spectrum metal halide 
lamps, an intermediate number of colonies under red to far-red light or red to blue, and the lowest number of colonies under red light (16). Furthermore, colonies on leaves grown under red light exhibited sparse mycelium and reduced conidiation compared with the other light treatments (16). Because powdery mildews are biotrophic, it is not possible from studies fects of light upon the pathogen from those light has been associated with increased plant resistance in other pathosystems (e.g.. leaf spot disease of broad bean [Vicia faba L.] caused by Alternaria tenuissima [14] and chocolate spot disease of broad bean caused by Botrytis cinerea [8]). Recently, it has been reported that red light induced resistance of cucumber plants against powdery mildew via higher levels conducted thus far to separate direct efexerted through the host. Exposure to red

of $\mathrm{H}_{2} \mathrm{O}_{2}$ and salicylic acid and stronger expression of defense genes (20). In continued work, we are investigating preinoculation exposure of host plants to red light to reveal possible stimulation of host defense responses in the suppressive impact of red light. Direct effects of such lighting on fungi would indicate the presence and operation of photoreceptors. Our results, wherein far-red light stimulated conidial formation and negated the effect of red light, may indicate the operation of a photoreceptor system in P. pannosa, such as that reported for Aspergillus nidulans $(3,13)$

Powdery mildews are among the most problematic pathogens to manage using chemical fungicides, particularly in greenhouse production systems. Resistance to benzimidazoles, demethylation-inhibiting, and strobilurin fungicides were reported in

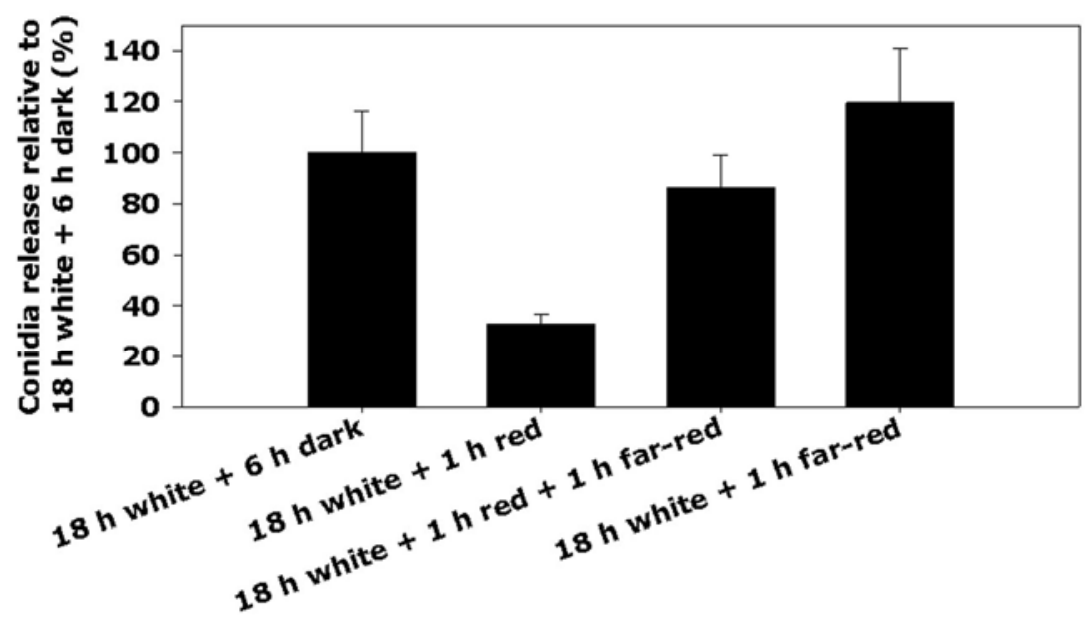

Light quality

Fig. 7. Effect of brief illumination during a dark period on productivity of conidia by Podosphaera pannosa on whole plants of Rosa $\times$ hybrida. Plants (kept at $18 \mathrm{~h}$ of day length) bearing 12-day-old mildew colonies were exposed to white light in a wind tunnel for $18 \mathrm{~h}$ per day followed by a 6-h dark period for 4 days. The dark period was interrupted by either $1 \mathrm{~h}$ of red light, $1 \mathrm{~h}$ of far- red light, or $1 \mathrm{~h}$ of red light followed by $1 \mathrm{~h}$ of far-red light (experiment was repeated three times). Treatment means are reported as percentages relative to $18 \mathrm{~h}$ of white light $+6 \mathrm{~h}$ of darkness (control). Bars indicate one standard error of the mean.

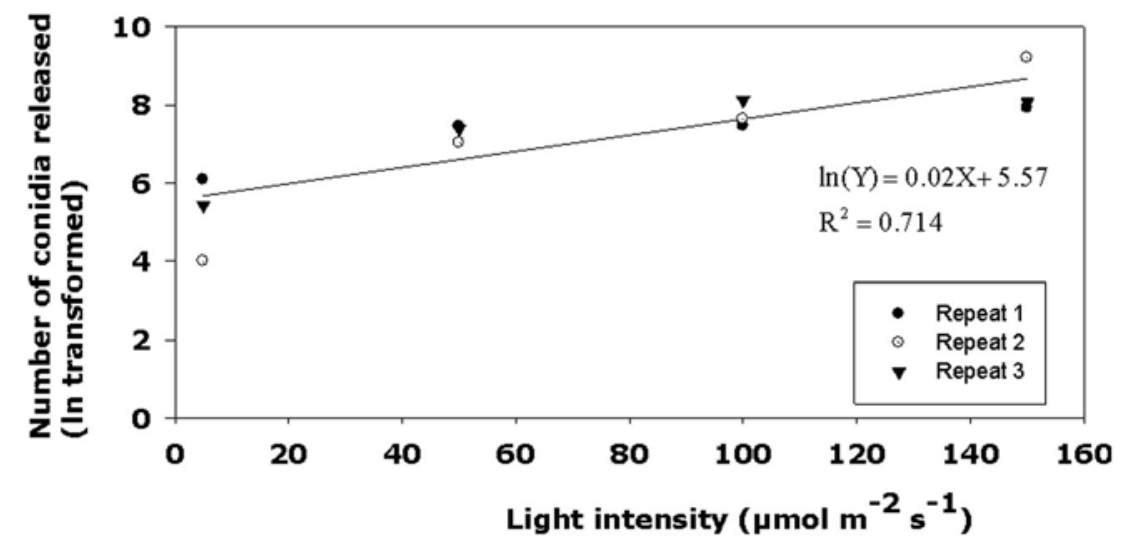

Fig. 8. Effect of light intensity on productivity of conidia by Podosphaera pannosa on whole plants of Rosa $\times$ hybrida in a wind tunnel. Plants bearing 12-day-old mildew colonies were exposed to white light at various intensities for $18 \mathrm{~h}$ per day followed by $6 \mathrm{~h}$ of darkness for 4 days (experiment was repeated three times). Treatment means were transformed to natural logs before regression. several powdery mildew pathosystems within 2 to 5 years after commercial deployment of these fungicide classes (5). Although the degree of disease suppression we have obtained in our preliminary studies is not comparable with the performance of the most effective fungicides in the absence of resistance, the continued availability of highly effective fungicides cannot be guaranteed. Our results provide an additional means of disease suppression that could potentially be exploited to reduce selection for resistance to fungicides, or to use in combination with partial disease resistance and cultural practices to produce rose plants in systems where deployment of conventional fungicides is not an option. Manipulation of day length and light quality using modern lighting technology $(4,11,17,18)$ might also be useful in other greenhouse crops where powdery mildew may be problematic (e.g., tomato, cucumber, and several ornamentals), and perhaps within selected field-grown crops.

\section{ACKNOWLEDGMENTS}

Financial support for this work was provided by the Norwegian Research Council and The Norwegian State Educational Loan Fund. We thank the technicians at the Centre for Plant Research (SKP) and Norwegian Institute for Agricultural and Environmental Research, Plant Health and Plant Protection Division; and D. Wenner and I. Brattberg for invaluable help during this work. The work described herein represents a portion of a dissertation submitted to the Norwegian University of Life Sciences (UMB) in partial satisfaction of the requirements for the $\mathrm{Ph} . \mathrm{D}$. degree in plant pathology.

\section{LITERATURE CITED}

1. Anonymous. 1998. Effects of active substances of plant protection products on biological control agents used in glasshouses. EPPO Bull. 28:425-431.

2. Barreiro, R., Guiamet, J. J., Beltrano, J., and Montaldi, E. R. 1992. Regulation of the photosynthetic capacity of primary bean leaves by the red:farred ratio and photosynthetic photon flux density of incident light. Physiol. Plant. 85:97-101.

3. Blumenstein, A., Veinken, K., Tasler, R., Purschwitz, J., Veith, D., Frankenberg-Dinkel, N., and Fischer, R. 2005. The Aspergillus nidulans phytochrome FphA represses sexual development in red light. Curr. Biol. 15:18331838.

4. Bourget, C. M. 2008. An introduction to light emitting diodes. HortScience 43:1944-1946.

5. Daughtrey, M. L., and Benson, D. M. 2005. Principles of plant health management for ornamental plants. Annu. Rev. Phytopathol. 43:141-169.

6. Elad, Y. 1997. Effect of filtration of solar light on the production of conidia by field isolates of Botrytis cinerea and on several diseases of greenhouse grown vegetables. Crop Prot. 16:635-642.

7. Hopkins, W. G. 1999. Introduction to Plant Physiology. John Wiley \& Sons, Inc., New York.

8. Islam, S. Z., Honda, Y., and Arase, S. 1998. Light-induced resistance of broad bean against Botrytis cinerea. J. Phytopathol. 146:479-485.

9. Moe, R., Grimstad, S. O., and Gislerod, H. R. 2006. The use of artificial light in year round production of greenhouse crops in Norway. Acta Hortic. 711:35-42. 
10. Mor, Y., and Halevy, A. H. 1984. Dual effect of light on flowering and sprouting of rose shoots. Physiol. Plant. 61:119-124.

11. Morrow, R. C. 2008. LED lighting in horticulture. HortScience 43:1947-1950.

12. Pettersen, R. I., Moe, R., and Gislerød, H. R. 2007. Growth of pot roses and post-harvest rate of water loss as affected by air humidity and temperature variations during growth under continuous light. Sci. Hortic. 114:207213

13. Purchwitz, J., Muller, S., Kastner, C., Schoser, M., Haas, H., Espeso, E. A., Atoui, A., Calvo, A. M., and Fischer, R. 2008. Functional and physical interaction of blue and red light sensors in Aspergillus nidulans. Curr. Biol. 18:255-259.

14. Rahman, M. Z., Honda, Y., and Arase, S. 2003. Red light induced resistance in broad bean (Vicia faba L.) to leaf spot disease caused by
Alternaria tenuissima. J. Phytopathol. 151:8691.

15. Saebo, A., Krekling, T., and Appelgren, M. 1995. Light quality affects photosynthesis and leaf anatomy of birch plantlets in vitro. Plant Cell Tiss. Org. 41:177-185.

16. Schuerger, A. C., and Brown, C. S. 1997. Spectral quality affects disease development of three pathogens on hydroponically grown plants. HortScience 32:96-100.

17. Suthaparan, A., Herrero, M. L., Pettersen, R. I., Torre, S., Stensvand, A., Gadoury, D. M., and Gislerød, H. R. 2008. Effect of day length on formation, release and germination of powdery mildew conidia in roses and severity of the disease. (Abstr.) J. Plant Pathol. 90 (Suppl. 2):191.

18. Suthaparan, A., Stensvand, A., Torre, S., Herrero, M., L., Pettersen, R. I., Gadoury, D. M., and Gislerød, H. R. 2010. Continuous lighting reduces conidial production and germinability in the rose powdery mildew pathosystem. Plant Dis. 94:339-344.

19. Suthaparan, A., Torre, S., Stensvand, A Herrero, M., L., Pettersen, R. I., Gadoury, D. M., and Gislerød, H. R. 2009. Day length extension and red light reduces powdery mildew in greenhouse roses. Proc. 6th Int Sym. Light Hortic. Tsukuba, Japan.

20. Wang, H., Jiang, Y. P., Yu, H. J., Xia, X. J., Shi, K., Zhou, Y. H., and Yu, J. Q. 2010. Light quality affects incidence of powdery mildew, expression of defence related genes and associated metabolism in cucumber plants. Eur. J. Plant Pathol. 127:125-135.

21. Yorio, N. C., Goins, G. D., and Kagie, H. R. 2001. Improving spinach, radish and lettuce growth under red light emitting diodes (LEDs) with blue light supplementation. HortScience 36:380-383. 